\title{
The Prevalence of Cardiovascular Disease Risk Factors and the Framingham Risk Score in Patients Undergoing Percutaneous Intervention Over the Last 17 Years by Gender: Time-trend Analysis From the Mayo Clinic PCI Registry
}

\author{
Moo-Sik Lee ${ }^{1,2}$, Andreas J. Flammer ${ }^{2}$, Hyun-Soo Kim ', Jee-Young Hong' ${ }^{1}$ Jing Li ${ }^{2}$, Ryan J. Lennon ${ }^{3}$, Amir Lerman ${ }^{2}$ \\ ${ }^{1}$ Department of Preventive Medicine, Konyang University College of Medicine, Daejeon, Korea; ${ }^{2}$ Division of Cardiovascular Diseases, Department of \\ Medicine, Mayo Clinic, Rochester, MN; ${ }^{3}$ Division of Biomedical Statistics and Informatics, Mayo Clinic, Rochester, MN, USA
}

Objectives: This study aims to investigate trends of cardiovascular disease (CVD) risk factor profiles over 17 years in percutaneous coronary intervention $(\mathrm{PCl})$ patients at the Mayo Clinic.

Methods: We performed a time-trend analysis within the Mayo Clinic PCI Registry from 1994 to 2010. Results were the incidence and prevalence of CVD risk factors as estimate by the Framingham risk score.

Results: Between 1994 and 2010, 25519 patients underwent a PCI. During the time assessed, the mean age at PCI became older, but the gender distribution did not change. A significant trend towards higher body mass index and more prevalent hypercholesterolemia, hypertension, and diabetes was found over time. The prevalence of current smokers remained unchanged. The prevalence of ever-smokers decreased among males, but increased among females. However, overall CVD risk according to the Framingham risk score (FRS) and 10-year CVD risk significantly decreased. The use of most of medications elevated from 1994 to 2010, except for $\beta$-blockers and angiotensin converting enzyme inhibitors decreased after 2007 and 2006 in both baseline and discharge, respectively. Conclusions: Most of the major risk factors improved and the FRS and 10-year CVD risk declined in this population of PCI patients. However, obesity, history of hypercholesterolemia, hypertension, diabetes, and medication use increased substantially. Improvements to blood pressure and lipid profile management because of medication use may have influenced the positive trends.

Key words: Cardiovascular diseases, Percutaneous coronary intervention, Trends, Risk factors

Received: March 12, 2014 Accepted: June 6, 2014

Corresponding author: Amir Lerman, MD

2001 st Street SW, Rochester, MN 55905, USA

Tel: +1-507-255-4152, Fax: +1-507-255-7798

E-mail: lerman.amir@mayo.edu

This is an Open Access article distributed under the terms of the Creative Commons Attribution Non-Commercial License (http://creativecommons.org/licenses/by$\mathrm{nc} / 3.0 / /$ which permits unrestricted non-commercial use, distribution, and reproduction in any medium, provided the original work is properly cited.

\section{INTRODUCTION}

Cardiovascular disease (CVD) is the one of major cause of mortality and morbidity in the world. CVD made up to 17.3 million of global deaths in 2008 , among which 7.6 million were due to coronary heart disease (CHD). In 2007, one-quarter of all deaths in the US originated from heart diseases, nearly 700 000 deaths in one year. CVD mortality and morbidity are also increasing due to sociodemographic, economic, and lifestyle 
transitions in developing countries [1]. However, CVD mortality decreased over 20 years, likely caused by a decrease in smoking and consumption of saturated fat, improved control of cardiovascular risk factors (cvRF) in general and clinical treatment of acute coronary disease in developed countries [1]. However, morbidity continued high rate and CVD is nevertheless the one of major cause of premature death in developed countries [2].

CVD have been related to many risk factors, and about $75 \%$ of CVD can be caused by traditional risk factors [3]. Although, in the overall population, the prevalence of cvRF have declined during the past 30 years [4], there is a vague information on the temporal trends of cvRF profiles [5], especially among patients referred for a percutaneous coronary intervention ( $\mathrm{PCl})$. The recognition of trends in cvRF profiles is important, especially as the current risk prediction models such as the Framingham risk score (FRS) are based on risk profiles from decades prior.

Thus, the purpose of this study was to investigate the trend in $\mathrm{CvRF}$ and the FRS in patients undergoing $\mathrm{PCl}$ in the hospitalbased registry over a 17-year period. Temporal trends in the medical treatments used as well as the usefulness and predictability of the FRS in patients undergoing $\mathrm{PCl}$ were evaluated.

\section{METHODS}

\section{Patients Selection}

We analyzed data of all $\mathrm{PCl}$ patients included in the Mayo Clinic PCI Registry in Rochester, Minnesota from January 1, 1994 to December 31, 2010 were included in this study. Patients undergoing $\mathrm{PCl}$ were prospectively followed in the registry that collected demographic, clinical, angiographic, and procedural data. Immediate and in-hospital events were recorded, and each patient was surveyed by telephone using a standardized questionnaire at 6 months and 1 year after the procedure, and then annually. The supervisor of this registry audited $10 \%$ of all records for data integrity. Relevant clinical information was abstracted from medical records. For patients who underwent multiple $\mathrm{PCl}$ within a single hospitalization, only the first $\mathrm{PCl}$ of that hospitalization was included. This study was approved by the Mayo Clinic Institutional review board, and patients who denied use of their records for research were excluded $(n=530$, 653 hospitalizations). During the study period, $26172 \mathrm{PCl}$ hospitalizations of 20711 unique patients were performed. After exclusion for patients who refused authorization of their records, 25519 hospitalizations were included for analysis.

\section{Collected Information}

Data retrieved from the $\mathrm{PCl}$ Registry included general characteristics (hospital ID, date of the PCl, age, sex, and family history of heart disease) and cvRF profiles (smoking status, presence of diabetes mellitus [DM], hypertension, hypercholesterolemia, height, and weight) [6]. Medicine use at baseline (within 3 days before the $\mathrm{PCl}$ ) and at discharge was recorded if patients were taking aspirin, $\beta$-blocker, angiotensin converting enzyme (ACE) inhibitor, or any other lipid lowering drugs. Hypercholesterolemia was defined as a history of higher than 240 $\mathrm{mg} / \mathrm{dL}$ for total cholesterol. Hypertension was defined as a documented history of hypertension that was being treated with medication. A patient was considered to have a history of myocardial infarction (MI) if Ml occurred at least 7 days prior to $\mathrm{PCl}$. Cholesterol and blood pressure (BP) values were retrieved from electronic medical records. BP values within one year prior to $\mathrm{PCl}$ were deemed acceptable; if multiple measures were found, the measure occurring on the date closest to $\mathrm{PCl}$ was recorded. BP values within one year prior to $\mathrm{PCl}$ were acceptable; if multiple measures were found, the measure occurring on the date closest to $\mathrm{PCl}$ was recorded. Cholesterol values within 2 years and prior to 2 months post $\mathrm{PCl}$ were acceptable; the maximum value (minimum for high-density lipoprotein cholesterol [HDL-C]) recorded closest to the $\mathrm{PCl}$ was recorded in the event of multiple measurements. These data were used to calculate the estimated risk of CVD using the FRS sheet [7], and cvRFs were treated as absent if data required for calculating the FRS were missing.

\section{Statistics}

Continuous variables are presented as mean \pm standard deviation or as median (interquartile range, Q1, Q3). Discrete data are presented as frequencies and percentages. Patients were stratified into three groups of 5-year intervals based on the date of the $\mathrm{PCl}$ to analyze trends among variables. The three groups included patients who had a PCl in 1994 to 1999, 2000 to 2005 , or 2006 to 2010, respectively. Analysis of variance with a linear contrast analysis was used to assess the trend among continuous variables, and the Cochran-Armitage trend test was used for comparison of proportions in the total population as well as within gender subgroups. Additionally, using linear regression for continuous variables and logistic regression for binary variables, we tested whether an interaction existed between gender and time to understand if the linear trend over time for men and women was identical. 
All statistical analyses were performed with SAS version 9.2 (SAS Inc., Cary, NC, USA). All tests were 2-tailed with a significance level of 0.05 .

\section{RESULTS}

A total of 25519 underwent a PCl at the Mayo Clinic and gave permission for follow-up from 1994 to 2010. The clinical characteristics and the FRS 5-year trends of the 25519 patients in the 3 periods are presented in Supplemental Table 1. The number of patients who underwent a PCl initially increased from 1994 to 1999, then plateaued from 2000 to 2005, and finally decreased from 2006 to 2010 ( $p$ for trend $<0.001$ ). For the total population, the mean age was $66.5 \pm 12.1$ years, and 18 $068(71 \%)$ patients were male. The mean age when patients received a $\mathrm{PCl}$ slightly increased across each interval ( $p$ for trend $<0.001$ ), but males still comprised the majority of patients throughout follow up ( $p$ for trend $=0.520$ ).

$\mathrm{BP}$ and lipid profiles improved for the patients who received a $\mathrm{PCl}$ most recently ( $p$ for trend $<0.001$ ); however, body mass index (BMI), hypercholesterolemia, hypertension, and DM showed an increasing trend ( $p$ for trend $<0.001$ ). Ten-year CVD risk and the FRS increased from 1994 to 1999, decreased from 2000 to 2006, and then slightly increased from 2006 to 2010. In men and women, the FRS and 10-year CVD risk tended to decrease over time ( $p$ for trend $<0.001$ for all). However, the FRS was higher in women than that in men for all intervals. The 10year CVD risk was higher in men than that in women for all in- tervals ( $p$ for trend $<0.001$ men vs. women). The prevalence of ever-smokers decreased in men ( $p$ for trend $<0.001$ ), but increased in women ( $p=0.042)$. Systolic BP, diastolic BP, low-density lipoprotein cholesterol (LDL-C), DM, and hypertension showed a significantly different trend between the genders ( $p$ for trend $<0.001$ men vs. women). However, age, total cholesterol, HDL-C, and the proportion of current smokers were not significantly different between genders over time (Supplemental Table 1, Figures 1-3).

Supplemental Table 2 presents the trends of BMI and number of patients with a history of hypercholesterolemia and/or $\mathrm{Ml}$ over the three intervals. The mean BMI and proportion of patients with a history of hypercholesterolemia increased over time, however they varied by time, and were different between genders ( $p$ for trend $<0.001$ men vs. women). The proportion of female patient with a history of MI was higher than male over time, but no significant difference of trend between each gender-specific trend was found (Figure 4).

Supplemental Table 3 shows trends relating to the use of pharmacological treatments over time. The use of most of medications increased over time, but $\beta$-blockers dramatically declined after 2007 and ACE inhibitors after 2006 at both baseline and discharge. ACE inhibitor use and lipid lowering drug use on discharge significantly differed over time between the genders ( $p$ for trend $=0.003$ in ACE inhibitor, 0.016 in lipid lowering drug, men vs. women) (Figure 5).

The average number of points that contributed to the total FRS for each component was plotted in Figure 3. Age was not
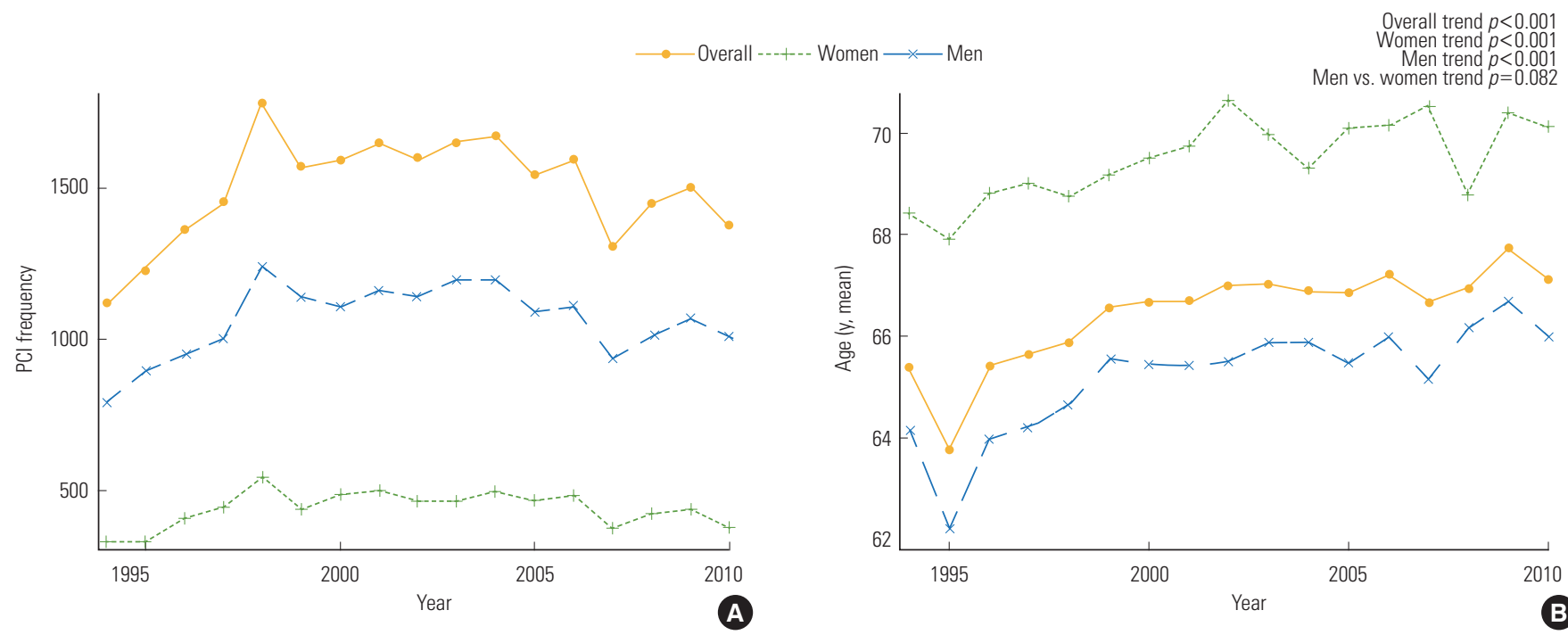

Figure 1. Distribution of total percutaneous coronary intervention (PCI) patient population (A) and age (B) by the year and by gender from 1994 to 2010. 

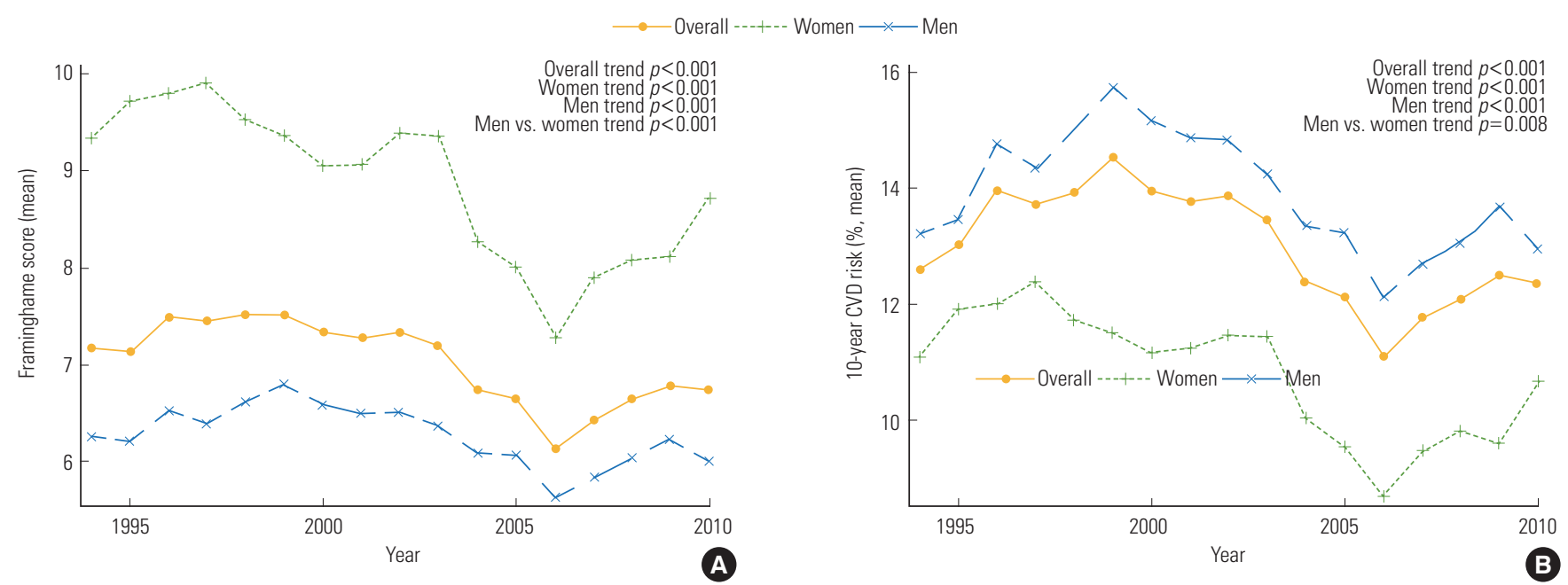

Figure 2. Trend of the Framingham risk score (A) and 10-year cardiovascular disease (CVD) risk (B) by gender in patients having percutaneous coronary intervention from 1994 to 2010.

added to the plot because the average was around 5.5 to 6 points and was flat, so it hindered the ability to see the other trends. According to our plot, BP and HDL-C had the greatest influence on the FRS calculation.

\section{DISCUSSION}

Despite the decline of CHD mortality, CHD remains the one of major cause of mortality in America. However, few studies have reported on cvRF status of $\mathrm{PCl}$ patients, and pervious results have been controversial. One study reported a progressive rise in the risk profile of patients undergoing PCl [8]. Our large single-center registry study adds to the previous studies by reporting on the temporal trends and characteristics of cvRFs using recent data.

Identifying changes to underlying risk factors is important for future planning on medical policies and administration for prevention. cvRFs of $\mathrm{CHD}$ co-act to increase CHD risk [9]. Therefore, integrated predictors or indicators for clinical and epidemiological evaluation and the prediction of disease status and prognosis are needed.

In this study, we revealed a decreasing trend for the FRS and 10-year CVD risk over time, likely due to the significant decrease in BP and increase in HDL-C as a result of medication effects or therapeutic interventions. We have suggested this relationship by analyzing the trend of each cvRF and the changes to the contribution of each risk factor to the total FRS by year.

The concept of cvRFs and the FRS has lead to the development of effective managements and preventive intervention in clinical management and the ability to estimate global risk scores of CHD. The FRS [10] is usually used score to estimate an 10-year risk of CVD. But, in spite of the ready used application of the FRS, it can be limited to apply the certain patients [11]. Atherosclerosis often does so as a life-threatening condition (examples, acute MI or stroke). Some of them previously would have been grouped as at low or moderate risk by the FRS [12]. Our results also suggest that there are limitations and in applying the FRS to $\mathrm{PCl}$ patients.

We found that the FRS had a higher trend in women than men; however, the 10-year CVD risk remained higher in men than did women over time. The data regarding gender variation, mechanism, and outcome effect with CHD are very complicated and controversial [13]. The mechanism underlying the 10-year lag in CHD development in women is not completely understood, but may be related, at least in part, to the protective effects of endogenous estrogen in premenopausal women. Overall, the risk factor prevalence in women was higher than that in men. The risk factor prevalence in female should be much higher than that in male to lead to the onset of CHD at the same age as in male, because CHD typically appears 10 years later in female [14].

Over time, the mean age that patients underwent $\mathrm{PCl}$ became older in our study. Advancing age is a contributing factor for the development of CHD in men and women [15]. Female tend to comprise the majority of older adults, and this demographic change has important implications for providing health care. This trend in increasing age over time may have originated because age increases the absolute baseline risk; 

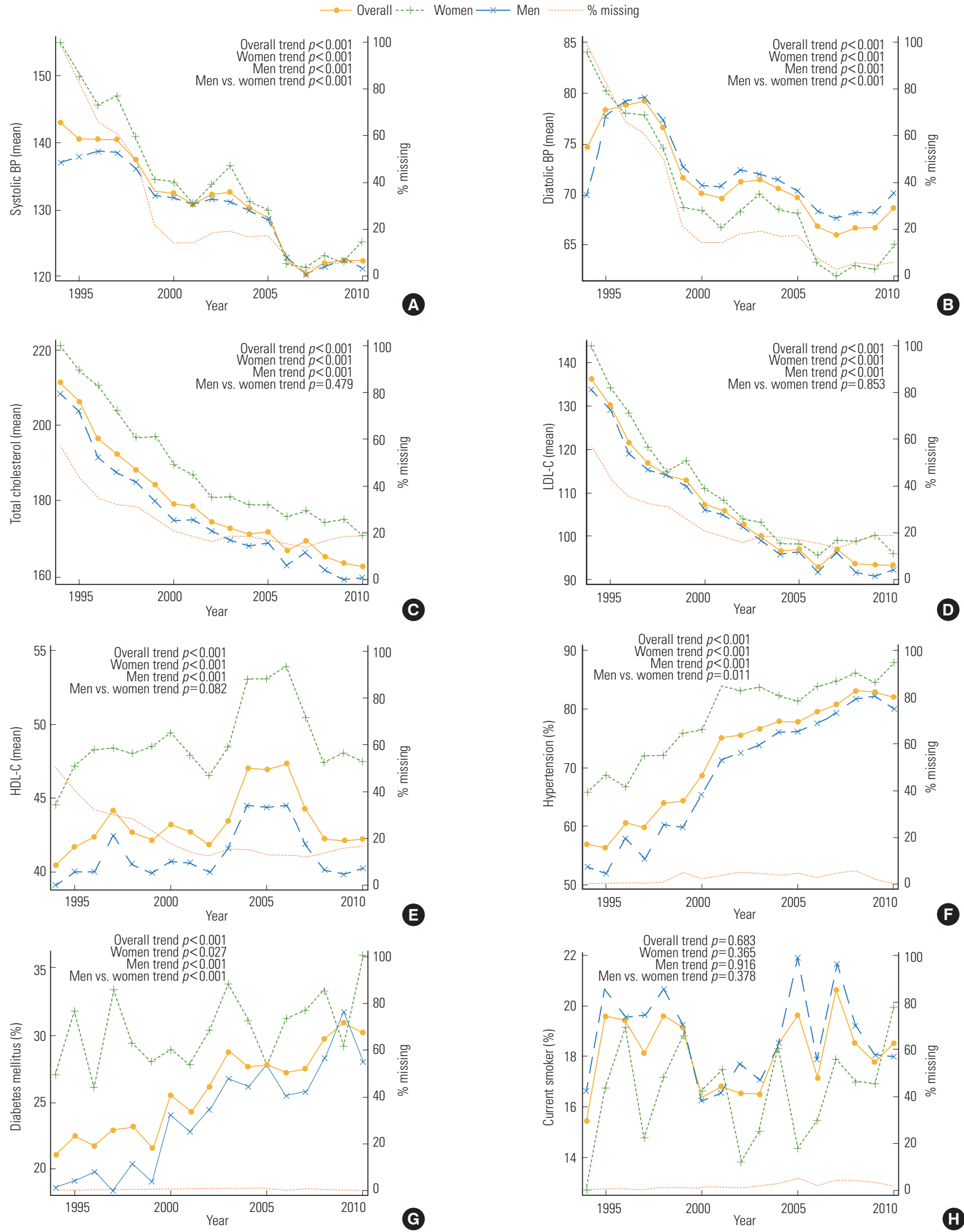

Figure 3. Trends of the components of Framingham risk score, including systolic blood pressure (BP) (A), diastolic BP (B), total cholesterol (C), low-density lipoprotein cholesterol (LDL-C) (D), high-density lipoprotein cholesterol (HDL-C) (E), hypertension (F), diabetes (G), and smoking (H) among percutaneous coronary intervention patients from 1994 to 2010. 

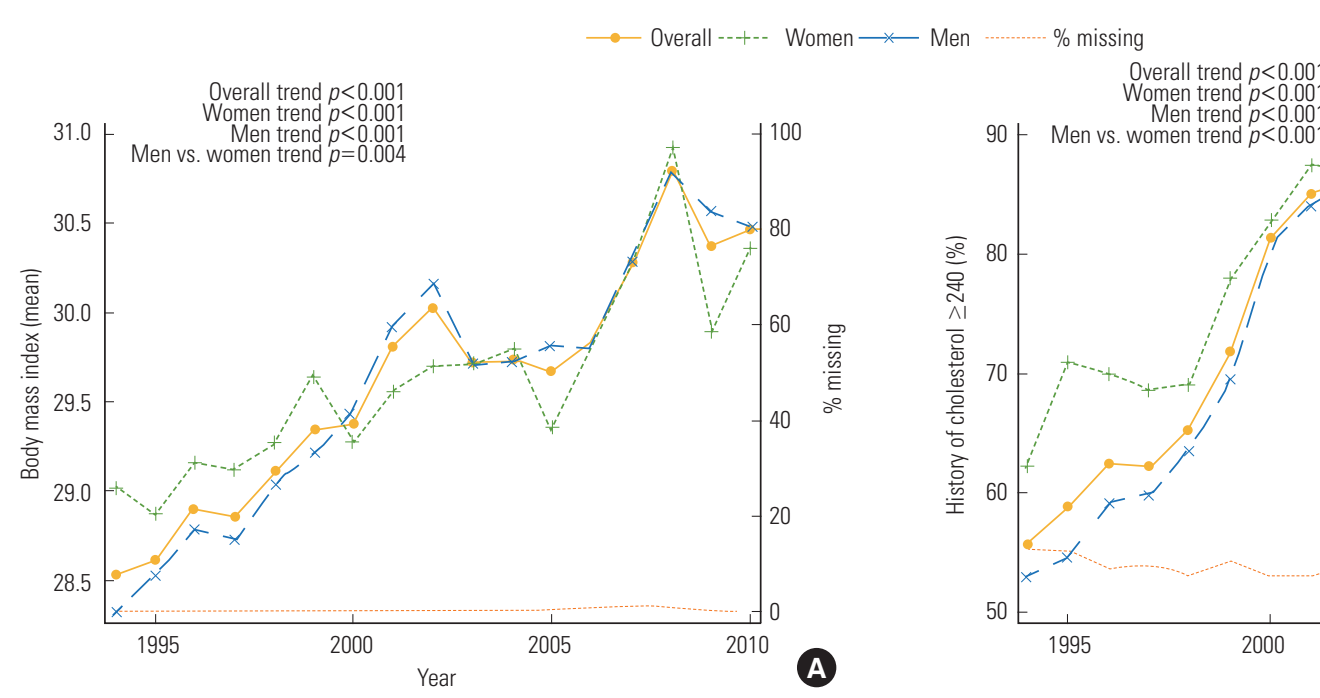

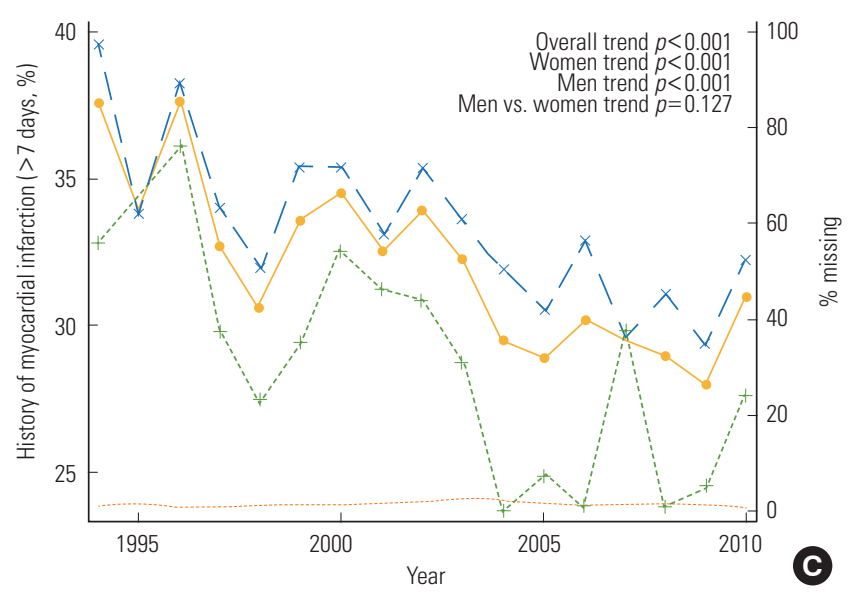

therefore, risk factor free patient will tend to present for a PCI at a much older age once their absolute baseline risk increases sufficiently to evoke a significant disease prevalence [16]. Moreover, this result may have been due to a survivor bias because patients with traditional risk factors tend to expire at more young age than those without traditional risk factors do [16].

Systolic BP is the most prominent risk factor as a target for treatment and for prognosis [17]. Combined systolic and diastolic hypertension and isolated systolic hypertension are documented risks for morbidity and onset of CHD in both genders [18]. In this study, BP declined rapidly, however the presence of hypertension increased continuously over time because hypertension was defined as a documented history of hypertension being treated with medication. Our result also showed that the trend for systolic BP, diastolic BP, and hypertension were significantly higher in women than that in men. These results are similar with those at the national level. The incidence of hypertension in whole life has been rising in 10-year recently and is

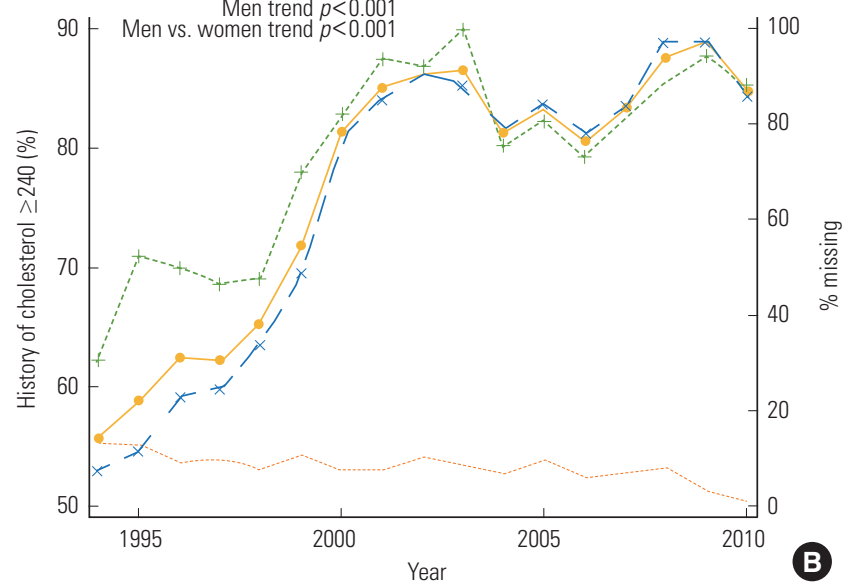

Figure 4. Trends of other cardiovascular risk factors including body mass index (A), history of hypercholesterolemia ( $>240$ $\mathrm{mg} / \mathrm{dL}$ ) (B), and history of myocardial infarction (C) by gender in percutaneous coronary intervention patients from 1994 to 2010.

now $90 \%$ in the US [19]. A national study of the US (NHANESA) from 2005 to 2008 reported that $33.5 \%$ of the US adults 20 years old or more have hypertension, and the hypertension prevalence is almost same status between the genders [9]. Moreover, the prevalence of hypertension tends to increase with age and reaches nearly $57 \%$ in male and $61 \%$ in female in those 65 to 74 years in the US [15]. Glaser et al. [20] from the Treat Angina with Aggrastat and Determine Cost of Therapy with an Invasive or Conservative Strategy-Thrombolysis in Myocardial Infarction 18 (TACTICS-TIMI 18) study reported that women patients were older and had higher rates of hypertension than the men did.

In this study, total cholesterol and LDL-C decreased continuously over time, but HDL-C increased overall. These results were consistent with that of previous studies. In the INTERHEART study, dyslipidemia was the most important CVD risk factor [3]. Dyslipidemia is defined by increased triglyceride levels ( $\geq 150 \mathrm{mg} / \mathrm{dL}$ ), decreased HDL-C levels ( $<40 \mathrm{mg} / \mathrm{dL}$ ), and increased LDL-C [17]. Hypertriglyceridemia also is known as an 

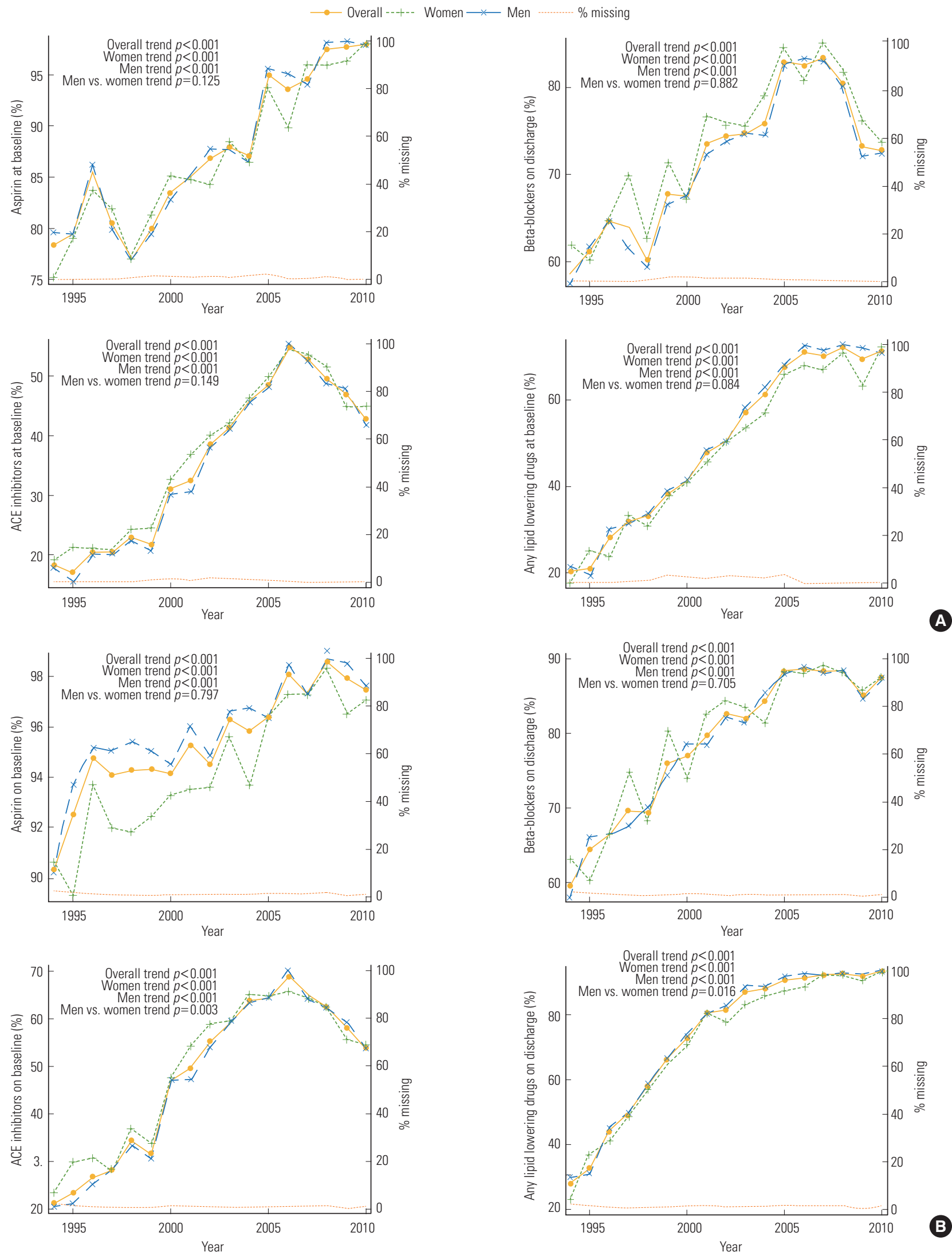

Figure 5. Trend of medication use at baseline (A) and on discharge (B) by gender in percutaneous coronary intervention patients from 1994 to 2010. ACE, angiotensin converting enzyme. 
independent $\mathrm{CHD}$ risk factor. Because it was associated with increased status in atherogenic particles. LDL-C also are strong atherogenic and lead to rapid onset of CHD. The Adult Treatment Panel III suggested a fasting triglyceride objective of $<150 \mathrm{mg} / \mathrm{dL}$ [21]. Many kinds of epidemiologic studies have demonstrated conclusive evidence that low status of LDL-C improves the patient's prognosis of CHD [22]. The risk of CVD and death all-cause improved in rate to the decrease in LDL-C levels achieved during management [23].

Approximately $15 \%$ of the US adults 20 years of age or older have total cholesterol levels $\geq 240 \mathrm{mg} / \mathrm{dL}$ [9]. In our PCI patients, the prevalence of hypercholesterolemia was average at $78.0 \%$. The proportion of all patients with a history of hypercholesterolemia increased over time, and this trend differed between genders.

Systolic BP dramatically declined at two critical points in 1997 and 2003. Diastolic BP also declined in a similar pattern with systolic BP, and these two critical points were the same points when the hypertension guidelines changed. In 1976, the Joint National Committee on Prevention, Detection, Evaluation, and Treatment of High Blood Pressure published the report firstly, and the most recent report JNC 7 was released in 2003. The Adult Treatment Panel published clinical guidelines on the Detection, Evaluation, and Treatment of High Blood Cholesterol in Adults in 1988, and succeeded by the second and third versions and an update in 2004. The Clinical Guidelines on the Identification, Evaluation, and Treatment of Overweight and Obesity in Adults were published in 1998. We believe that by following the updated hypertension guidelines toward medication use, blood pressure and lipid profiles improved in our study population.

DM contributes to raised morbidity and mortality, and contributes to CVD complications [24]. DM patients are at markedly increased risk of CHD, silent myocardial ischemia and MI [17]. Additionally, DM patients are prone to hypertension cause by increased activity in the renin-angiotensin-aldosterone system, salt retention, and highly stimulated sympathetic nerve system. Within the population, the proportion of patients who develop diabetes is increasing in recent decades [25]. In 2008, the American Heart Association estimated that there are 18300000 DM patients in the US, representing $8 \%$ of the adult population, and that the prevalence of DM is dramatically increasing [9]. Statistics report that two epidemics of obesity and DM may see a reversal in the dramatic improvement made against CVD in 10year recently $[17,22]$. The dramatic elevated in obesity over the two decade has led to an increase in type 2 women DM [15]. The proportion of DM increased 7.0\% (men 9.0\%, women 3.0\%) per year between 1994 to 1999 and 2006 to 2010. Gandhi et al. [26] reported that the proportion of MI with DM elevated 3\% in one year from 1979 to 1998 in Olmsted County, Minnesota. It is consistent with other studies that the prevalence of DM in female is higher than that in male, so DM is a strong risk factor in female [27]. However, in this study, the proportion of DM patients is increasing at a faster rate in men than that in women; relative changes from 1994-1999 to 2006-2010 were $9.0 \%$ in men, $3.0 \%$ in women.

The long-term health effects of smoking on CVD are serious, and a dose-response relationship was known between the status of smoking and the incidence of MI [3]. Cigarette smoking is harmful at any age. Furthermore, smoking acts synergistically co-act with other traditional cvRFs to dramatically increase the risk related with each risk factor individually [28]. In this study, although the prevalence of current smokers was stable over time, the prevalence of ever-smokers decreased in men patients $(p<0.001)$, but increased in women patients $(p=0.042)$. Our results were inconsistent with a report from 2005; the temporal decrease in smoking showed among Ml patients is consistent with the general population over the past few decades [29]. Despite four decades of progress, $21 \%$ of male and $17.5 \%$ of female continued smoke cigarettes among all American $\geq$ 18 years of age as of 2010 [9].

Excess weight is independently associated with increased CHD risk in both genders [30]. A high BMI was most important contributing factor of mortality from CVD [31]. BMI has reported a graded inter-relationship with MI [17]. Obesity also explains the increasing prevalence of acute $\mathrm{MI}$ in younger patients [32]. Obesity in abdomen has been connected with metabolic disorder, such as hypertriglyceridemia, hyperinsulinemia, insulin resistance, hypertension, and DM. The temporal increases in obesity observed for Ml cases are consistent with trends over time in recent decades [29]. There has been a dramatic epidemics in overweight and obesity over the past 25 years in the America [33], with the obesity rate among the adult population having risen from $15 \%$ in 1980 to $34 \%$ in 2008 [34]. In our population $\mathrm{PCl}$ patients, mean $\mathrm{BMI}$ increased over time in the total population and in men and women separately. Nevertheless, the trends and clinical meaning of these trends for $\mathrm{PCl}$ patients remain vague.

It also is important to recognize the trend of medication therapy over time among our PCl patients, particularly isch- 
emic events after $\mathrm{PCl}$ are commonly associated with thromboembolism [35]. We identified the trends of pharmacological drugs for treatment over time. The use of most of medications increased over time, however $\beta$-blocker and ACE inhibitor use dramatically declined after 2007 and 2006, respectively, at baseline and upon discharge. The results showed significant trend difference between men and women in the use of ACE inhibitor and lipid lowering drugs at discharge. Increasing trend of drug use was consistent with the results of other studies. In community study, the trends of temporal medication use increased, and earlier studies suggested a low status of using evidence-based management after $\mathrm{Ml}$, especially among older people, women, and DM patients [36]. Women have been found less likely than men are to receive thrombolytic therapy, aspirin, heparin, and $\beta$-blockers [37]. Perschbacher et al. [36] reported the application of ACE inhibitors, aspirin, and $\beta$-blockers to average $42 \%, 75 \%$, and $44 \%$ using administrative data (1994 to 1997) and $72 \%, 91 \%$, and 33\% according to community surveillance studies (1993 to 1998), respectively. In this study, use of ACE inhibitors and $\beta$-blockers in $\mathrm{PCl}$ patients increased over time, but abruptly declined after 2006 and 2008, respectively. This situation can be due to discourage application of $\beta$-blockers and replaced ACE inhibitors by angiotensin receptor blockers. It have been proposed to include $\beta$-blockers in hypertension guidelines as a first therapeutic choice for over 30-year. However, controversy over the use and effectiveness of $\beta$-blockers in CVD exist. Currently, older $\beta$-blockers are not typically a first choice in the treatment of primary hypertension because of various controversies and introduction of novel drug [38]. Based on evidence from randomized clinical trials, the American College of Cardiology and American Heart Association guidelines recommend the application of ACE inhibitors in chronic heart failure or MI and left ventricular dysfunction patients, while angiotensin receptor blockers are reserved for those who cannot treat ACE inhibitors [39]. Angiotensin receptor blockers afford well-known efficacy and indication that make sure their many medication alternatives, including those subject to the adverse effects of ACE inhibitors medication [40].

This study could limit its broad application and generalization because of a retrospective analysis from a single institution, but represents the largest temporal trends analysis of coronary risk factors in patients undergoing $\mathrm{PCl}$ over time. We did not comment on trends in genetic factors, related environmental factors, other conventional risk factors, and clinical charac- teristics and outcomes. Our study cannot rule out selection bias as the patients referred for tertiary-level care centers may include more severe cases of CHD than that in the general population. Since the FRS commonly estimate risk in the healthy person, $\mathrm{PCl}$ patients will show an essentially higher risk score than that in the general people. Therefore, the result of this study should be further examined in different another settings. The quality of our data relies on the quality of the hospital coding of the PCl registry. There can be some miscoding and reporting errors of cvRFs and related data. The characteristics of this study were described as natural and controlling for confounder like sex or age was not performed. Further studies are needed to identify these differences.

We have demonstrated that the FRS, 10-year CVD risk, BP, and lipid profiles improved over time in patients who underwent a PCl. The age distribution significantly shifted toward older age with time, but the gender distribution did not changed. However, obesity, history of hypercholesterolemia, and comorbidities like hypertension and diabetes increased substantially. The decreased overall CVD risk likely originated from the significant improvement in the BP and lipid profiles due to medication use. Furthermore, we observed that the FRS, 10-year CVD risk, systolic $B P$, diastolic $B P, L D L-C, D M$, hypertension, $B M I$, and history of hypercholesterolemia had a significantly different trend between men and women. However, age, total cholesterol, HDL-C, and the proportion of current smokers did not change with time. The use of most of the medications markedly increased over time; however, $\beta$-blockers and ACE inhibitors dramatically declined. Moreover, a significant trend difference between the genders in the use of ACE inhibitor and lipid lowering drug on discharge was found.

Thus, the results of our study suggest that future studies and clinical and public interventions are needed to evaluate these differences.

\section{CONFLICT OF INTEREST}

The authors have no conflicts of interest with the material presented in this paper.

\section{REFERENCES}

1. Wijeysundera HC, Machado M, Farahati F, Wang X, Witteman W, van der Velde $\mathrm{G}$, et al. Association of temporal trends in risk factors and treatment uptake with coronary heart disease mo- 
rtality, 1994-2005. JAMA 2010;303(18):1841-1847.

2. Heron M, Hoyert DL, Murphy SL, Xu J, Kochanek KD, TejadaVera B. Deaths: final data for 2006. Natl Vital Stat Rep 2009; 57(14):1-134.

3. Yusuf S, Hawken S, Ounpuu S, Dans T, Avezum A, Lanas F, et al. Effect of potentially modifiable risk factors associated with myocardial infarction in 52 countries (the INTERHEART study): case-control study. Lancet 2004;364(9438):937-952.

4. Arnett DK, McGovern PG, Jacobs DR Jr, Shahar E, Duval S, Blackburn $\mathrm{H}$, et al. Fifteen-year trends in cardiovascular risk factors (1980-1982 through 1995-1997): the Minnesota Heart Survey. Am J Epidemiol 2002;156(10):929-935.

5. Khawaja FJ, Rihal CS, Lennon RJ, Holmes DR, Prasad A. Temporal trends (over 30 years), clinical characteristics, outcomes, and gender in patients $\leq 50$ years of age having percutaneous coronary intervention. Am J Cardiol 2011;107(5):668-674.

6. Labarthe DR. Epidemiology and prevention of cardiovascular diseases: a global challenge. 2nd ed. Sudbury: Jones and Bartlett Publishers; 2011, p. 74-79.

7. Wilson PW, D'Agostino RB, Levy D, Belanger AM, Silbershatz H, Kannel WB. Prediction of coronary heart disease using risk factor categories. Circulation 1998;97(18):1837-1847.

8. Hoffman SJ, Holmes DR Jr, Rabinstein AA, Rihal CS, Gersh BJ, Lennon RJ, et al. Trends, predictors, and outcomes of cerebrovascular events related to percutaneous coronary intervention: a 16-year single-center experience. JACC Cardiovasc Interv 2011;4(4):415-422.

9. Roger VL, Go AS, Lloyd-Jones DM, Benjamin EJ, Berry JD, Borden WB, et al. Heart disease and stroke statistics: 2012 update. A report from the American Heart Association. Circulation 2012;125(1):e2-e220.

10. D'Agostino RB Sr, Vasan RS, Pencina MJ, Wolf PA, Cobain M, Massaro JM, et al. General cardiovascular risk profile for use in primary care: the Framingham Heart Study. Circulation 2008; 117(6):743-753.

11. Rubinshtein R, Yang EH, Rihal CS, Prasad A, Lennon RJ, Best PJ, et al. Coronary microcirculatory vasodilator function in relation to risk factors among patients without obstructive coronary disease and low to intermediate Framingham score. Eur Heart J 2010;31(8):936-942.

12. Detrano R, Guerci AD, Carr JJ, Bild DE, Burke G, Folsom AR, et al. Coronary calcium as a predictor of coronary events in four racial or ethnic groups. N Engl J Med 2008;358(13):1336-1345.

13. Hasdai D, Bell MR, Grill DE, Berger PB, Garratt KN, Rihal CS, et al. Outcome $>$ or $=10$ years after successful percutaneous translu- minal coronary angioplasty. Am J Cardiol 1997;79(8):1005-1011.

14. Knopp RH, Aikawa K. Estrogen, female gender, and heart disease. In: Topol EJ, Califf RM, editors. Textbook of cardiovascular medicine. 2nd ed. Philadelphia: Lippincott Williams \& Wilkins; 2002, p. 175.

15. Tsang TS, Barnes ME, Gersh BJ, Hayes SN. Risks of coronary heart disease in women: current understanding and evolving concepts. Mayo Clin Proc 2000;75(12):1289-1303.

16. Khot UN, Khot MB, Bajzer CT, Sapp SK, Ohman EM, Brener SJ, et al. Prevalence of conventional risk factors in patients with coronary heart disease. JAMA 2003;290(7):898-904.

17. O'Keefe JH, Carter MD, Lavie CJ. Primary and secondary prevention of cardiovascular diseases: a practical evidence-based approach. Mayo Clin Proc 2009;84(8):741-757.

18. Fiebach NH, Hebert PR, Stampfer MJ, Colditz GA, Willett WC, Rosner $\mathrm{B}$, et al. A prospective study of high blood pressure and cardiovascular disease in women. Am J Epidemiol 1989; 130(4):646-654.

19. Chobanian AV, Bakris GL, Black HR, Cushman WC, Green LA, Izzo JL Jr, et al. The Seventh Report of the Joint National Committee on Prevention, Detection, Evaluation, and Treatment of High Blood Pressure: the JNC 7 report. JAMA 2003;289(19): 2560-2572

20. Glaser R, Herrmann HC, Murphy SA, Demopoulos LA, DiBattiste PM, Cannon CP, et al. Benefit of an early invasive management strategy in women with acute coronary syndromes. JAMA 2002;288(24):3124-3129.

21. Smith SC Jr, Allen J, Blair SN, Bonow RO, Brass LM, Fonarow $\mathrm{GC}$, et al. AHA/ACC guidelines for secondary prevention for patients with coronary and other atherosclerotic vascular disease: 2006 update. Endorsed by the National Heart, Lung, and Blood Institute. Circulation 2006;113(19):2363-2372.

22. Lavie CJ, Milani RV. Shedding light on high-density lipoprotein cholesterol: the post-ILLUMINATE era. J Am Coll Cardiol 2008;51(1):56-58.

23. Bybee KA, Lee JH, O'Keefe JH. Cumulative clinical trial data on atorvastatin for reducing cardiovascular events: the clinical impact of atorvastatin. Curr Med Res Opin 2008;24(4):12171229.

24. Conaway DG, O'Keefe JH, Reid KJ, Spertus J. Frequency of undiagnosed diabetes mellitus in patients with acute coronary syndrome. Am J Cardiol 2005;96(3):363-365.

25. Burke JP, O'Brien P, Ransom J, Palumbo PJ, Lydick E, Yawn BP, et al. Impact of case ascertainment on recent trends in diabetes incidence in Rochester, Minnesota. Am J Epidemiol 2002; 
155(9):859-865.

26. Gandhi GY, Roger VL, Bailey KR, Palumbo PJ, Ransom JE, Leibson CL. Temporal trends in prevalence of diabetes mellitus in a population-based cohort of incident myocardial infarction and impact of diabetes on survival. Mayo Clin Proc 2006;81(8): 1034-1040.

27. Barrett-Connor EL, Cohn BA, Wingard DL, Edelstein SL. Why is diabetes mellitus a stronger risk factor for fatal ischemic heart disease in women than in men? The Rancho Bernardo Study. JAMA 1991;265(5):627-631.

28. Keil U, Liese AD, Hense HW, Filipiak B, Doring A, Stieber J, et al. Classical risk factors and their impact on incident non-fatal and fatal myocardial infarction and all-cause mortality in southern Germany. Results from the MONICA Augsburg cohort study 1984-1992. Monitoring Trends and Determinants in Cardiovascular Diseases. Eur Heart J 1998;19(8):1197-1207.

29. Gregg EW, Cheng YJ, Cadwell BL, Imperatore G, Williams DE, Flegal KM, et al. Secular trends in cardiovascular disease risk factors according to body mass index in US adults. JAMA 2005; 293(15):1868-1874.

30. Jousilahti P, Tuomilehto J, Vartiainen E, Pekkanen J, Puska P. Body weight, cardiovascular risk factors, and coronary mortality: 15-year follow-up of middle-aged men and women in eastern Finland. Circulation 1996;93(7):1372-1379.

31. Calle EE, Thun MJ, Petrelli JM, Rodriguez C, Heath CW Jr. Bodymass index and mortality in a prospective cohort of U.S. adults. N Engl J Med 1999;341(15):1097-1105.

32. Madala MC, Franklin BA, Chen AY, Berman AD, Roe MT, Peterson ED, et al. Obesity and age of first non-ST-segment elevation myocardial infarction. J Am Coll Cardiol 2008;52(12):979985.
33. Flegal KM, Carroll MD, Ogden CL, Johnson CL. Prevalence and trends in obesity among US adults, 1999-2000. JAMA 2002; 288(14):1723-1727.

34. Organisation for Economic Cooperation and Development. Health at a glance 2011: OECD indicators. Paris: OECD Publishing; 2011 , p. 8.

35. White HD, Chew DP, Dauerman HL, Mahaffey KW, Gibson CM, Stone GW, et al. Reduced immediate ischemic events with cangrelor in $\mathrm{PCl}$ : a pooled analysis of the CHAMPION trials using the universal definition of myocardial infarction. Am Heart J 2012;163(2):182-190.

36. Perschbacher JM, Reeder GS, Jacobsen SJ, Weston SA, Killian $J M$, Slobodova A, et al. Evidence-based therapies for myocardial infarction: secular trends and determinants of practice in the community. Mayo Clin Proc 2004;79(8):983-991.

37. Chandra NC, Ziegelstein RC, Rogers WJ, Tiefenbrunn AJ, Gore $J M$, French WJ, et al. Observations of the treatment of women in the United States with myocardial infarction: a report from the National Registry of Myocardial Infarction-I. Arch Intern Med 1998;158(9):981-988.

38. Lindholm LH, Carlberg B, Samuelsson O. Should beta blockers remain first choice in the treatment of primary hypertension? A meta-analysis. Lancet 2005;366(9496):1545-1553.

39. Agency for Healthcare Research and Quality. Comparative effectiveness of angiotensin converting enzyme inhibitors or angiotensin II receptor blockers added to standard medical therapy for treating stable ischemic heart disease. Rockville: Agency for Healthcare Research and Quality; 2009, p. 2.

40. Catanzaro DF, Frishman WH. Angiotensin receptor blockers for management of hypertension. South Med J 2010;103(7): 669-673. 


\section{Journal of}

Supplemental Table 1. Trends of the Framingham risk score and its component by gender and 5-year interval

\begin{tabular}{|c|c|c|c|c|c|c|}
\hline \multirow[b]{2}{*}{ Variables } & \multirow{2}{*}{$\begin{array}{c}\text { Total } \\
\text { population } \\
(n=25519)\end{array}$} & \multicolumn{3}{|c|}{ 5-Year interval } & \multirow{2}{*}{$\begin{array}{c}\text { Relative } \\
\text { change } \\
\text { (difference, \%) }\end{array}$} & \multirow{2}{*}{$\underset{\text { trend }}{p \text { for }}$} \\
\hline & & $\begin{array}{c}1994-1999 \\
(n=8539)\end{array}$ & $\begin{array}{l}2000-2005 \\
(n=9729)\end{array}$ & $\begin{array}{c}2006-2010 \\
(n=7251)\end{array}$ & & \\
\hline Framingham risk score & $7.0(3.3)$ & $7.4(3.2)$ & $7.1(3.3)$ & $6.5(3.2)$ & -0.9 & $<0.001$ \\
\hline 10-Year CVD risk (\%) & $11.0(7.0,18.0)$ & $11.0(8.0,18.0)$ & $11.0(7.0,18.0)$ & $11.0(7.0,14.0)$ & 0 & $<0.001$ \\
\hline Age (y) & $66.5(12.1)$ & $65.5(11.8)$ & $66.9(12.1)$ & $67.2(12.3)$ & 1.7 & $<0.001$ \\
\hline $\mathrm{SBP}(\mathrm{mmHg})$ & $128.8(22.1)$ & $136.8(21.9)$ & $131.2(22.4)$ & $121.9(19.7)$ & -14.9 & $<0.001$ \\
\hline $\mathrm{DBP}(\mathrm{mmHg})$ & $70.2(13.4)$ & $75.6(12.5)$ & $70.6(13.4)$ & $67.1(13.0)$ & -8.5 & $<0.001$ \\
\hline Hypertension & $17785(72.0)$ & $5095(61.0)$ & $6982(75.0)$ & $5708(82.0)$ & 21 & $<0.001$ \\
\hline $\mathrm{LDL}$ (mg/dL) & $104.3(38.5)$ & $119.7(37.5)$ & $101.6(36.5)$ & $94.0(37.8)$ & -25.7 & $<0.001$ \\
\hline $\mathrm{TC}(\mathrm{mg} / \mathrm{dL})$ & $177.4(45.8)$ & $194.1(45.0)$ & $174.9(42.1)$ & $165.8(46.9)$ & -28.3 & $<0.001$ \\
\hline Ever smoker & $16088(63.0)$ & $5431(64.0)$ & $6134(63.0)$ & $4523(62.0)$ & -2 & 0.11 \\
\hline \multicolumn{7}{|l|}{ Men } \\
\hline Framingham risk score & $6.3(2.6)$ & $6.5(2.5)$ & $6.4(2.7)$ & $6.0(2.5)$ & -0.5 & $<0.001$ \\
\hline 10-Year CVD risk (\%) & $11.0(9.0,18.0)$ & $14(9.0,18.0)$ & 11. $(9.0,18.0)$ & $11.0(7.0,18.0)$ & -3 & $<0.001$ \\
\hline Age (y) & $65.3(11.8)$ & $64.2(11.5)$ & $65.6(11.8)$ & $66.0(12.0)$ & 1.8 & $<0.001$ \\
\hline $\mathrm{SBP}(\mathrm{mmHg})$ & $128.2(21.4)$ & $135.4(21.2)$ & $130.6(21.9)$ & $121.7(19.1)$ & -13.7 & $<0.001$ \\
\hline $\mathrm{DBP}(\mathrm{mmHg})$ & $71.3(13.0)$ & $76.3(12.3)$ & $71.4(13.1)$ & $68.6(12.6)$ & -7.7 & $<0.001$ \\
\hline Hypertension & $12078(69.0)$ & $3355(57.0)$ & $4733(73.0)$ & $3990(80.0)$ & 23 & $<0.001$ \\
\hline $\operatorname{LDL}(\mathrm{mg} / \mathrm{dL})$ & $103.2(37.4)$ & $118.4(35.6)$ & $100.7(35.8)$ & $92.4(36.6)$ & -26 & $<0.001$ \\
\hline Framingham risk score & $8.9(4.0)$ & $9.6(3.6)$ & $8.9(4.0)$ & $8.0(4.2)$ & -1.6 & $<0.001$ \\
\hline 10-Year CVD risk (\%) & $9.0(7.0,15.0)$ & $9.0(8.0,15.0)$ & $9.0(6.0,15.0)$ & $8.0(5.0,13.0)$ & -1 & $<0.001$ \\
\hline Age (y) & $69.5(12.2)$ & $68.7(11.7)$ & $69.9(12.4)$ & $70.0(12.7)$ & 1.3 & $<0.001$ \\
\hline $\mathrm{SBP}(\mathrm{mmHg})$ & $130.3(23.6)$ & $140.6(23.5)$ & $132.6(23.6)$ & $122.6(21.1)$ & -18 & $<0.001$ \\
\hline $\mathrm{DBP}(\mathrm{mmHg})$ & $67.5(14.0)$ & $73.7(13.0)$ & $68.4(13.8)$ & $63.3(13.5)$ & -10.4 & $<0.001$ \\
\hline Hypertension & 5707 (79.0) & $1,740(71.0)$ & $2249(82.0)$ & $1718(85.0)$ & 14 & $<0.001$ \\
\hline $\mathrm{LDL}(\mathrm{mg} / \mathrm{dL})$ & $107.1(41.1)$ & $123.3(41.9)$ & $103.8(38.0)$ & $97.9(40.4)$ & -25.4 & $<0.001$ \\
\hline $\mathrm{TC}(\mathrm{mg} / \mathrm{dL})$ & $186.2(47.2)$ & $204.7(47.3)$ & $182.9(44.1)$ & $175.0(46.7)$ & -29.7 & $<0.001$ \\
\hline $\mathrm{HDL}(\mathrm{mg} / \mathrm{dL})$ & $49.2(14.4)$ & $47.8(14.2)$ & $49.8(14.1)$ & $49.6(14.8)$ & 1.8 & $<0.001$ \\
\hline $\mathrm{DM}$ & $2245(30.0)$ & $728(29.0)$ & $851(30.0)$ & $666(32.0)$ & 3 & 0.04 \\
\hline Current smoker & $1203(16.0)$ & 412 (16.0) & 444 (15.0) & 347 (17.0) & 1 & 0.95 \\
\hline Ever smoker & $3546(48.0)$ & $1145(46.0)$ & $1384(48.0)$ & $1017(49.0)$ & 3 & 0.042 \\
\hline
\end{tabular}

Values are presented as mean $\pm S D$, number of patients (\%), or median (quartiles 1, 3).

CVD, cardiovascular disease; SBP, systolic blood pressure; DBP, diastolic blood pressure; LDL, low density lipoprotein; TC, total cholesterol; HDL, high density lipoprotein; DM, diabetic mellitus.

${ }^{1} A$ linear regression analysis was used to assess the trend for continuous variables, and the Cochran-Armitage trend test was used for the comparison of proportions. 
Supplemental Table 2. Trend of non-Framingham risk score variables for coronary heart disease by gender and 5-year interval

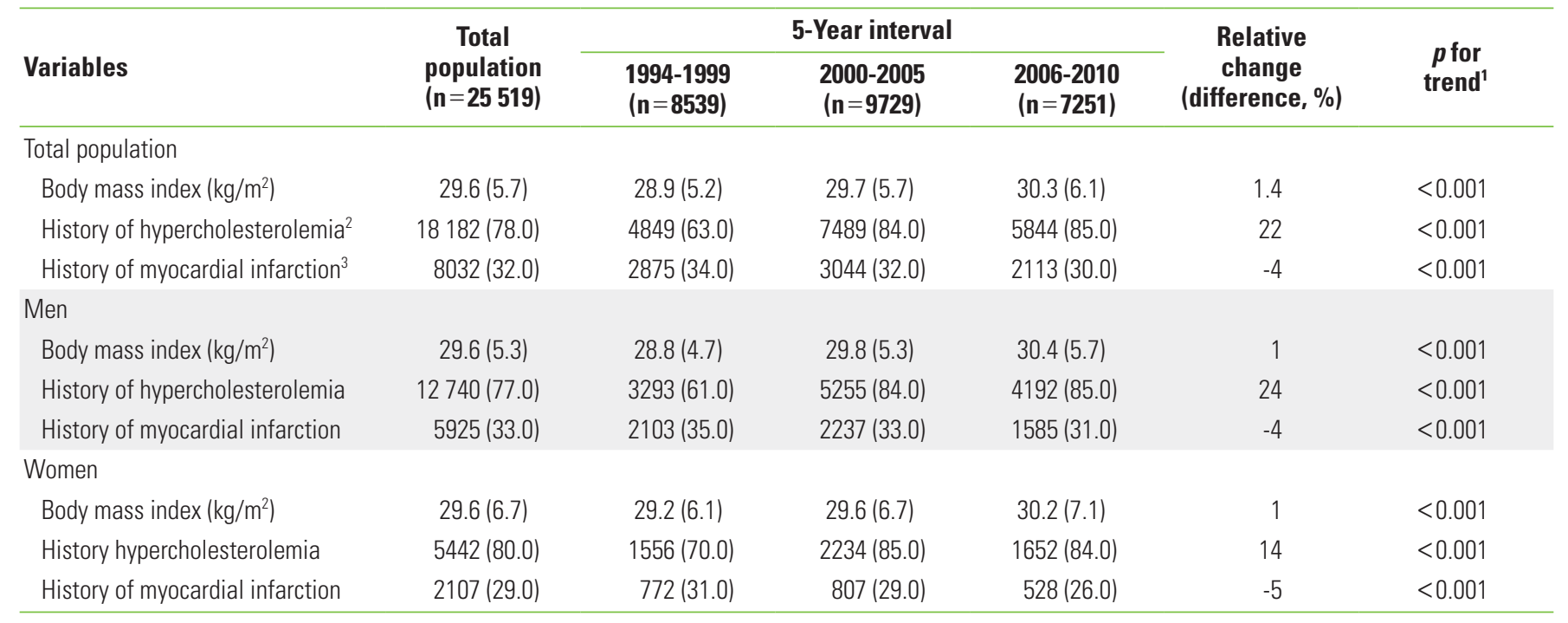

Values are presented as mean \pm SD or number of patients (\%).

${ }^{1} \mathrm{~A}$ linear regression analysis was used to assess the trend for continuous variables, and the Cochran-Armitage trend test was used for the comparison of proportions.

${ }^{2}$ Hypercholesterolemia was defined that a total cholesterol blood level $\geq 240 \mathrm{mg} / \mathrm{dL}$.

${ }^{3} \mathrm{~A}$ history of myocardial infarction was defined as a myocardial infarction event within 7 days of the percutaneous coronary intervention. 


\section{Journal of}

Supplemental Table 3. Trend of pharmaceutical therapy use by gender and 5-year interval

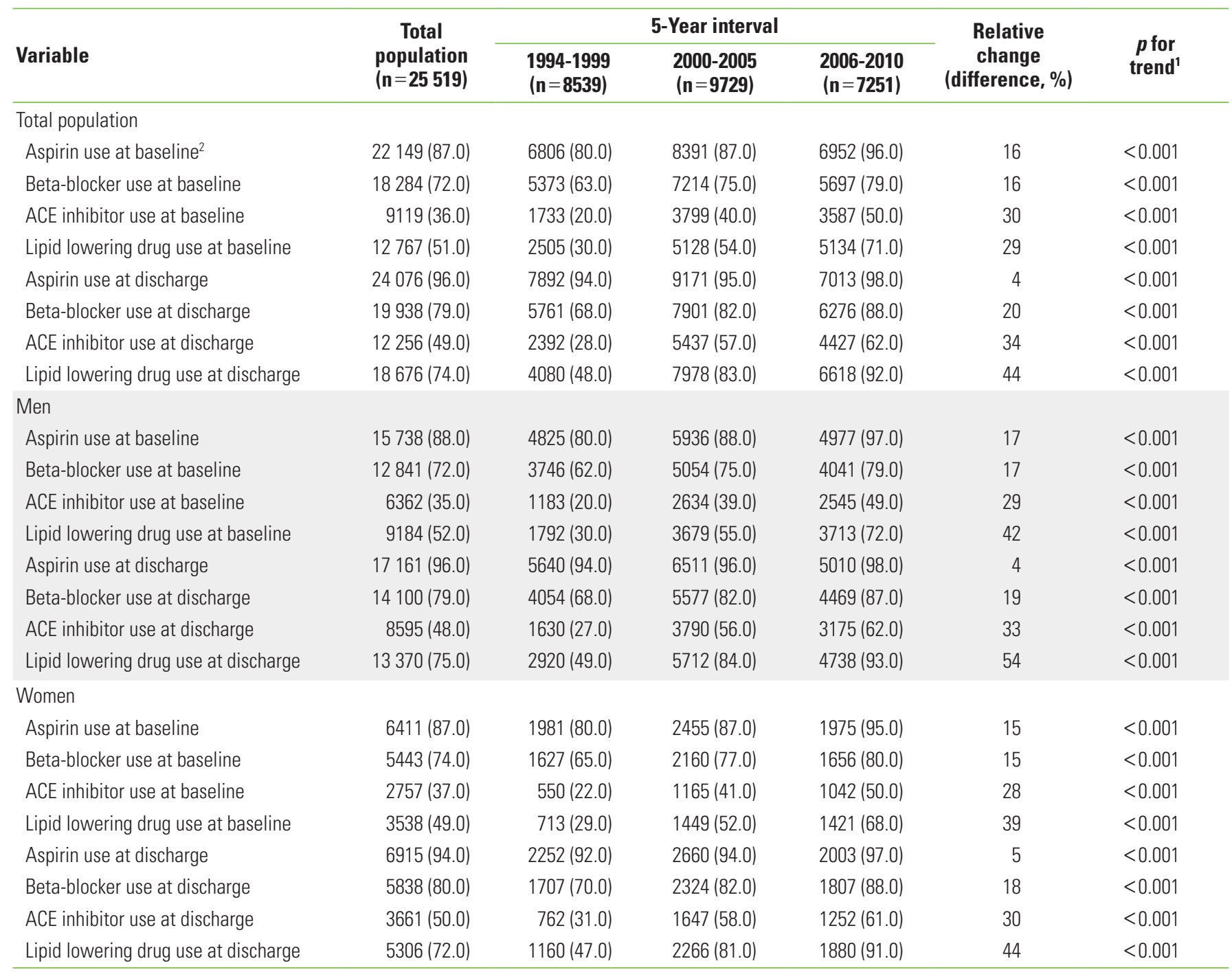

Values are presented as number of patients $(\%)$.

ACE, angiotensin converting enzyme.

${ }^{1}$ The Cochran-Armitage trend test was used to compare the proportions.

${ }^{2}$ Mean value at baseline for answering "yes" to whether the medication was used within 3 days before the percutaneous coronary intervention. 